\title{
Genetic variability in natural populations of Paspalum dilatatum Poir. analyzed by means of morphological traits and molecular markers
}

\author{
María Victoria García · Pedro A. Balatti · \\ Miguel J. Arturi
}

Received: 14 November 2005/ Accepted: 3 May 2006/ Published online: 4 January 2007

(C) Springer Science+Business Media B.V. 2006

\begin{abstract}
Native species show adaptive traits that are difficult to find in introduced species. The Pampas region in Argentina is a valuable nature reserve of grasses and Paspalum dilatatum Poir. is one of the most important grasses found there. Based on ploidy level and on morphological traits, five biotypes of $P$. dilatatum have been described. Two of them were included in this study: a tetraploid biotype with sexual reproduction and a pentaploid biotype with apomictic reproduction. We analyzed the genetic diversity in eight native populations from the Salado basin, Argentina, using both quantitative traits and molecular data (RAPD) with these aims: to obtain information of the degree of phenotypic variation in that area, to know which the pattern of distribution of this variation is and to look for
\end{abstract}

The article is part of a thesis presented by María Victoria García in partial fulfillment of the requirements for the Doctor's degree, Facultad de Ciencias Naturales y Museo, Universidad Nacional de La Plata, La Plata, Argentina.

M. V. García · P. A. Balatti · M. J. Arturi

Departamento de Ciencias Biológicas, Facultad de Ciencias Agrarias y Forestales, Universidad Nacional de La Plata, 60 y 119, 1900 La Plata, Buenos Aires, Argentina

\section{V. García ( $\square)$}

Department of Ecology and Environmental Science, University of Umeå, SE-891 87 Umeå, Sweden

e-mail: victoria.garcia@emg.umu.se association between molecular markers with populational or biotypic differentiation. Cluster analysis based on morphological data grouped the individuals of the different populations by ploidy level. Molecular markers showed the inverse situation because individuals were grouped by geographic origin as opposed to biotype. Moreover, since RAPD did not discriminate between biotypes with sexual or apomictic reproduction, they are probably not associated with mating system. The results let us conclude that polygenic traits such as LP, LBSR, NRT and NSP can discriminate between biotypes and molecular markers such as bands 12, 40, 19 and 46 can be used to discriminate among populations, probably because they detect neutral variation.

Keywords Apomictic grass - Natural variation · Dallisgrass $\cdot$ Paspalum dilatatum $\cdot$ Pentaploid biotype $\cdot$ Tetraploid biotype

\section{Introduction}

Paspalum dilatatum Poir. (dallisgrass) is an important summer forage grass in South America, whose place of origin includes Uruguay, South Brazil and Argentina (Holt 1956). This grass is a perennial and rhizomatous plant with smooth leaves and a strong root system and a panicle with 3-5 spikes (Burkart 1969). Dallisgrass starts to 
grow in early spring, before most warm season grasses, and continues until late fall (Holt 1956).

Because of the phylogeny of this genus is not well defined yet, taxonomic categories like "section" or other have not been assigned so far (Zuloaga, personal communication). In this way $P$. dilatatum is grouping into the informal group Dilatata, which includes other species clearly related such as, P. urvillei Steudel, P. pauciciliatum Hertel and P. dasypleurum Kuntze (Barreto 1974). The genus Paspalum includes many polyploid species, with a basic chromosome number of 10 (Quarín and Norrmann 1986). Based on ploidy level and on morphological traits, five biotypes of $P$. dilatatum have been described. The biotype "Flavescens" is most often found in southern Brazil, Uruguay and Argentina (Casa 1995). It is tetraploid $(2 n=4 x=40)$ with sexual reproduction, predominantly autogamous and have yellow anthers. The biotype "Common" predominates in the province of Buenos Aires, Argentina. It is pentaploid $(2 n=5 x=50)$, has apomictic reproduction, purple anthers and the highest forage quality of the biotypes. The reproductive system of these two biotypes was analyzed by Bashaw and Holt (1958).

The suitability of the pentaploid biotype as a forage grass is due to its adaptability to different soils, its perennial growth and its high dry matter yield production during summer (Carámbula 1982). The last character allows this species to fill the deficit in forage production during warm season (Pahlen 1986). However, its potential use as forage is reduced, at least in part, due to high susceptibility to the common biotype to the fungus Claviceps paspali (Burson et al. 1973). Infection by $C$. paspali results in the production of ergot, a sticky material, toxic to livestock if consumed in large quantities. The efficient use of this natural resource can only be optimized if its diversity is evaluated and quantified in some way.

Three other biotypes of $P$. dilatatum have also been described and are known as "Torres", "Uruguaiana" and "Uruguayan". These biotypes are hexaploid $(2 n=6 x=60)$, present different meiotic behavior and occur in different zones of South America. Burson et al. (1991) described these biotypes as pseudogamous and suggested that they developed aposporic apomictic embryonic sacs.

The origin of the tetraploid and pentaploid biotypes was established by means of cytological studies. The diploid species $P$. juergensii Hackel (genome $\mathrm{JJ}$ ) and $P$. intermedium Mourung (genome II) have been proposed as the likely genome donors of the yellow anther biotype (genome IIJJ) (Burson and Bennett 1972; Burson et al. 1973). Recently, Casa (1995) suggested, based on data from molecular markers studies, that $P$. intermedium and $P$. jurgensii are not the progenitors of $P$. dilatatum and proposed that future studies should include other Paspalum species from the Quadrifaria and Paniculata groups as potential donors of the II and JJ genomes, respectively. Also, slightly different forms of II genome were observed in four other diploid species of the Quadrifaria group: P. quadrifarium Nees, P. brunneum Poir, P. haumanii Parodi and P. densum Poir. (Espinoza and Quarín 2000). Burson (1991) suggested that the pentaploid biotype was originated from cross between the tetraploid and hexaploid "Uruguayan" biotype.

Morphological traits, in particular quantitative traits, have been used in these species to characterize and to assess the variability of natural populations (Percival and Couchman 1979; Pahlen 1986; García et al. 2002).

Molecular biology has allowed the development of rapid, sensitive, and specific screening methods to study genetic diversity. Molecular techniques like restriction fragment length polymorphisms (RFLPs) and random amplified polymorphic DNA (RAPDs) have been used in the genus Paspalum to study, for instance, genetic diversity (Liu et al. 1994; M'Ribu and Hilu 1996; Jarret et al. 1998; Pereira et al. 2000), the phylogenetic relationship among closely related species of this genus (Pereira et al. 1999; Casa 1995) and to analyze the mode of reproduction (Ortiz et al. 1997)

In the studied area, the populations of this species show a predominance of apomictic biotypes. Therefore, these populations, like populations of the autogamous biotypes, might show reduced variability within population and wide diversity among populations. In this work we analyze the genetic diversity in eight native 
populations of $P$. dilatatum from the Salado basin province of Buenos Aires, Argentina, using both quantitative traits and molecular data. The objectives of this work were: to obtain information of the degree of phenotypic variation in that area, to know which the pattern of distribution of this variation is and to look for association between molecular markers with populational or biotypic differentiation.

\section{Materials and methods}

Populations of $P$. dilatatum collected from eight different locations of the Salado river basin in the province of Buenos Aires (Argentina) were analyzed (Fig. 1). Around 20 individuals of each population were included in the quantitative traits analysis and 8 individuals as representatives of each population in the molecular analysis (Table 1). No tetraploid genotypes were found in the populations of Brandsen and Pereyra Iraola while in the rest of the populations both tetraploid and pentaploid biotypes were found. The ploidy level was established by anther color.

Soil characteristics and a lack of natural drainage explain why that the principal movement of water is vertical in the Salado river basin. Together with topographic variation these characteristics

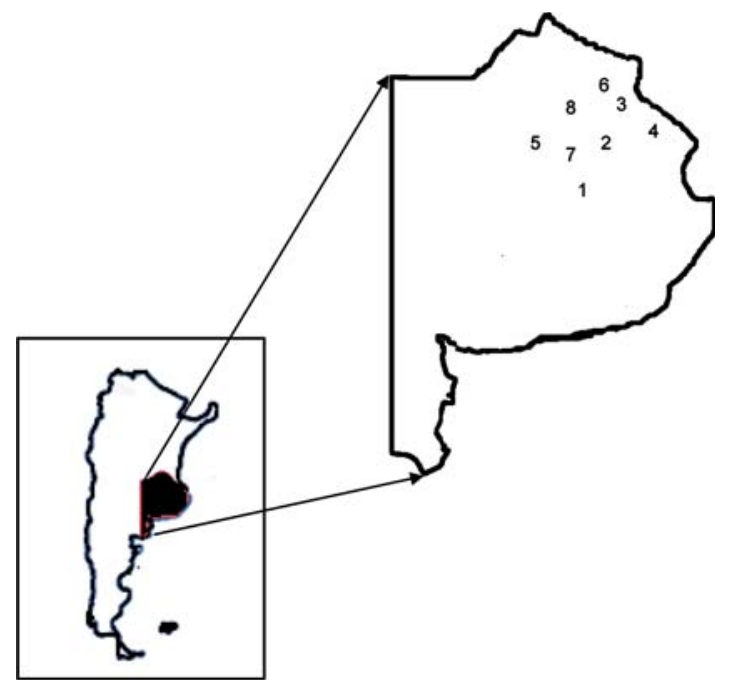

Fig. 1 Map showing the location of 8 population of Paspalum dilatatum. 1, Belgrano; 2, Brandsen; 3, La Plata; 4, Magdalena; 5, Monte; 6, Pereyra Iraola; 7, Ranchos; 8, San Vicente define heterogeneous vegetation (F. Grecco and V. Rossi 1997) in a region with a warm and wet climate.

Samples were taken from isolated plants (separated by at least $3 \mathrm{~m}$ ) to avoid sampling the same individual twice. Plants were kept in plastic pots with sandy soil and controlled irrigation.

\section{Quantitative characters}

Diversity at quantitative traits was evaluated by means of six reproductive and six vegetative characters of high forage value. The quantitative characters measured are resumed in Table 2. All the characters were measured on two reproductive tillers from each genotype. Because the characters LFL, WFL, $\mathrm{LL}_{2}$ and $\mathrm{WL}_{2}$ were correlated, two new characters: foliar area of the flag leaf and foliar area of the second leaf (FAFL and $\mathrm{FAL}_{2}$ ) were calculated as measurement of the surface area. These characters and \%SC were only used in multivariate analysis.

Another character included in the analysis was Resistance to Claviceps paspali $(\mathrm{RCp})$. It was determined by direct observation on two panicles per plant. Four levels of attack were considered: (1) Panicle without fungus, (2) $30 \%$ of infected panicle, (3) $60 \%$ of the panicle infected and (4) Panicle totally attacked.

RAPD markers

\section{DNA isolation}

Five hundred milligram of fresh leaf tissue was cut in small pieces, and transferred to $1.5 \mathrm{ml}$ Eppendorf tubes with three beads of glass $(3 \mathrm{~mm}$ diameter). Tubes were submerged in liquid nitrogen, vortexed for $1 \mathrm{~min}$ to grind the tissue and then DNA was isolated by adding $1 \mathrm{ml}$ of extraction buffer Rapid One Step Extraction (ROSE) (Steiner et al. 1995), washed twice with phenol and once with chloroform. Finally, DNA was precipitated with $1 \mathrm{vol}$ of isoamylalcohol and 10\% 3 M Sodium Acetate. The DNA quality was estimated by measuring the OD (optical density) at $260 / 280 \mathrm{~nm}$ in a spectrophotometer (Shimadzu Model UV-160A). 
Table 1 Collection sites of Paspalum dilatatum Poir. and number of plants analysed in each ploidy level

\begin{tabular}{|c|c|c|c|c|c|}
\hline \multirow[t]{3}{*}{ Population } & \multicolumn{4}{|c|}{ Genotypes analysed } & \multirow[t]{3}{*}{ Location } \\
\hline & \multicolumn{2}{|c|}{ Quantitative traits } & \multicolumn{2}{|c|}{ Molecular data } & \\
\hline & $2 n=4 x$ & $2 n=5 x$ & $2 n=4 x$ & $2 n=5 x$ & \\
\hline Belgrano & 5 & 14 & 1 & 7 & $35^{\circ} 51^{\prime} \mathrm{LS}, 58^{\circ} 35^{\prime} \mathrm{LW}$ \\
\hline Brandsen & - & 19 & - & 8 & $35^{\circ} 17^{\prime} \mathrm{LS}, 58^{\circ} 13^{\prime} \mathrm{LW}$ \\
\hline La Plata & 1 & 14 & 1 & 7 & $34^{\circ} 54^{\prime} \mathrm{LS}, 57^{\circ} 55^{\prime} \mathrm{LW}$ \\
\hline Magdalena & 6 & 14 & 4 & 4 & $35^{\circ} 00^{\prime} \mathrm{LS}, 57^{\circ} 41^{\prime} \mathrm{LW}$ \\
\hline Monte & 6 & 14 & 1 & 7 & $35^{\circ} 22^{\prime} \mathrm{LS}, 58^{\circ} 48^{\prime} \mathrm{LW}$ \\
\hline Pereyra Iraola & - & 19 & - & 8 & $34^{\circ} 52^{\prime} \mathrm{LS}, 58^{\circ} 08^{\prime} \mathrm{LW}$ \\
\hline Ranchos & 2 & 17 & 2 & 6 & $35^{\circ} 26^{\prime} \mathrm{LS}, 58^{\circ} 15^{\prime} \mathrm{LW}$ \\
\hline San Vicente & 12 & 9 & 4 & 4 & $35^{\circ} 03^{\prime} \mathrm{LS}, 58^{\circ} 30^{\prime} \mathrm{LW}$ \\
\hline
\end{tabular}

Table 2 Quantitative characters measured

* This character was registered by puncture

\begin{tabular}{ll}
\hline Quantitative characters & \\
\hline Vegetative characters & Reproductive characters \\
\hline Number of Nodes per Tiller (NNT) & Number of Reproductive Tillers (NRT) \\
Tiller Length (TL) & Length of Panicle (LP) \\
Length of Flag Leaf (LFL) & Length of Basal Spike Rachis (LBSR) \\
Width of Flag Leaf (WFL) & Number of Spikes per Panicle (NSP) \\
Length of 2nd Leaf (LL $)$ & Number of Spikelets per Panicle (NSpP) \\
Width of 2nd Leaf ( $\left.\mathrm{WL}_{2}\right)$ & Percentage of Spikelets with Caryopse (\%SC)* \\
\hline
\end{tabular}

\section{Polymerase chain reaction}

RAPD reactions were carried out in a final volume of 15 ul. About fifteen ng of genomic template DNA plus $10 \times$ reaction buffer $(50 \mathrm{mM} \mathrm{KCl}$, $10 \mathrm{mM}$ Tris- $\mathrm{HCl}, \mathrm{pH} 9.0 ; 1 \%$ Triton $\mathrm{X} 100$ ), $7.5 \mathrm{mg}$ BSA (bovine serum albumin, Sigma Chemical Corporation), $12 \mathrm{ng}$ of primer (DNAgency, Malvern USA), $0.2 \mathrm{mM}$ of each dNTPs (Promega Biotech Corporation), $1.5 \mathrm{mM} \mathrm{MgCl}_{2}$, and $1 \mathrm{U}$ Taq DNA polymerase (Highway Mol Biol-InBio-UNICEN, Tandil, BA, Arg) completed the reaction mixture. A thermocycler (Thermolyne Temp-Tronic ${ }^{\circledR}$ ) was programmed as follows: an initial denaturing step of $5 \mathrm{~min}$ at $94^{\circ} \mathrm{C}, 40$ cycles consisting each of a denaturing step of $45 \mathrm{~s}$ at $94^{\circ} \mathrm{C}, 60 \mathrm{~s}$ at $36^{\circ} \mathrm{C}$, and $60 \mathrm{~s}$ at $72^{\circ} \mathrm{C}$ with a final step of $7 \mathrm{~min}$ at $72^{\circ} \mathrm{C}$. Gels were then photographed under UV light with a Polaroid Camera DS34 and film type 667. The reactions were carried out with low stringency conditions of annealing for standardized the reaction for all the primers tested. Negative controls without template DNA was included in each round of reactions for distinguish between specific and unspecific reaction products.
Twenty-nine primers with sequences that corresponded to different primer series from Operon Tech. Corp. with G-C content between 60-70\% were tested (Table 3).

Data analysis

\section{Quantitative characters}

Using the collected data, we generated a distance matrix (DM) in the form of column $n \times$ row $t$ matrix. The DM was standardized to a zero mean and unity variance to reduce scale effects of the different characters measured. The analysis of the relationship between representative genotypes of the populations was made with a distance coefficient that indicates the genetic distance (GD). The mean taxonomic distance index (MTD) was applied. (Sneath and Sokal 1983). A phenogram was generated by applying the UPGMA (unweighted pair-group method using arithmetic averages) method as the clustering strategy.

The relevance of the characters in the discrimination of individuals was established by means of principal component analysis. This 
Table 3 Nucleotide sequence of 10 -mer primers used for RAPD genetic similarity analysis of eight natural population of Paspalum dilatatum Poir.
'OP' was derived by primers from operon Technologies, Alameda, CA

\begin{tabular}{|c|c|c|c|}
\hline Primer & Sequence & Primer & Sequence \\
\hline A 08 & $5^{\prime}$-ACGCACAACC-3' & OPE 08 & 5'-TCACCACGGT-3' \\
\hline OPA 02 & 5'-TGCCGAGCTG-3' & OPE 09 & $5^{\prime}$ GGGTAACGCC 3' \\
\hline OPA 05 & 5'-AGGGGTCTTG-3' & OPE 15 & 5'-ACGCACAACC-3' \\
\hline OPA 07 & 5'-GAAACGGGTG-3' & OPE 16 & 5'-GGTGACTGTG-3' \\
\hline OPA 09 & 5'-GGGTAACGCC-3' & OPE 18 & 5 AGGYGACCGT 3' \\
\hline OPA 10 & 5'-GTGATCGCAG-3' & OPE 19 & $5^{\prime}$-ACGGCGTATG-3' \\
\hline OPA 13 & 5'-CAGCACCCAC-3' & OPE 20 & 5'-AACGGTGACC-3' \\
\hline OPA 14 & 5'-TCTGTGCTGG-3' & OPF 10 & 5'-GGAAGCTTGG-3' \\
\hline OPA 20 & 5'-GTTGCGATCC-3' & OPG 03 & 5'-GAGCCCTCCA-3' \\
\hline OPB 10 & 5'-CTGCTGGGAC-3' & OPG 05 & 5'-CTGAGACGGA-3' \\
\hline OPB 15 & 5'-GGAGGGTGTT-3' & OPJ 13 & 5'-CCACACTACC-3' \\
\hline OPC 04 & 5'-CCGCATCTAC-3' & OPR 04 & 5'-CCCGTAGCAC-3' \\
\hline OPC 11 & 5'-AAAGCTGCGG-3' & OPW 13 & 5'-CACAGCGACA-3' \\
\hline OPC 19 & 5'-GTTGCCAGCC-3' & OLIGO P 124 & 5'-ATTGCGTCCGAG-3' \\
\hline OPC 20 & 5'-ACTTCGCCAC-3' & & \\
\hline
\end{tabular}

analysis departs from correlation matrix. Regression coefficient between the component and the character explains the contribution of each character to each component. The relative significance of characters for the first three components was analyzed.

The means of all characters were calculated for each population and biotype and Tukey's test was applied to contrast population means. Student $t$-test was used to determine whether differences between biotypes means were statistically significant. Also, variability between biotypes was tested by means of coefficient of variability applying non-parametric Mann-Whitney test $(U)$.

\section{Molecular characters}

RAPDs are dominant genetic markers that can not discriminate between homozygotes and heterozygotes (Ferreira and Grattapaglia 1996). In order to generate the DM, bands are analyzed as double state qualitative characters. During the construction of the DM it was assumed that a band strictly identifies one locus with two alleles and bands with different molecular weight correspond to different independent loci (Stewart and Excoffier 1996).

Genetic similarity (GS) was analyzed using one symmetric association coefficient and one asymmetric association coefficient. Simple Matching (SM) was used as symmetric association coefficient and Jaccard (CAJ) as asymmetric. SM is defined as $\mathrm{SM}=(a+d) /(a+b+c+d)$ and $\mathrm{CAJ}$ is defined as $\mathrm{CAJ}=a / a+b+c$. Where $a$ represents a band shared by two individuals (positive match), $b$ is a band present in one individual and absent in the other, $c$ is a band absent in one individual and present in the other and $d$ is a band absent in both (negative match) (Sneath and Sokal 1983). Symmetric coefficients consider the double absence of a band whereas asymmetric coefficients ignore it (Legendre and Legendre 1983). A phenogram for each coefficient was generated using UPGMA.

The relative significance of RAPD bands in population discrimination was analyzed by means of principal coordinate component from the similarity matrix. The contribution in the individual discrimination for the first three coordinates was analyzed.

\section{Correlation analysis}

Molecular and quantitative data were compared using Mantel correlation test. The correspondence Mantel test was performed to compare the distance and similarity matrices (Smouse et al. 1986). In this test, a correspondence measure $\left(r_{x y}\right)$ is calculated between the elements of two matrixes $X$ and $Y$. A high value of $r_{x y}$ indicates a lineal relation between the elements $X_{i j}$ and $Y_{i j}$ (Beer et al. 1993). Similarity values were transformed in genetic distance values by: GD = 1- (GS). 


\section{Results}

Quantitative characters

Table 4 shows mean values of the vegetative and reproductive characters.

The means for each population of the morphological characters measured were pairwise compared using the Tukey test, which makes use of the Studentized range (Steel and Torrie 1980). In general there were few significant differences among them. Characters such as LFL, NRT, NSP, LP, LBSR and NSpP can be grouped in only two subsets of means (Table 5).

Brandsen had higher mean values for seven characters, although not statistically different from the other populations. The genotypes from San Vicente were highly heterogeneous and had the lowest mean values of the morphological characters.

In the pentaploid biotype, vegetative and reproductive characters had significant higher values than individuals that were tetraploid, except NRT and NSP (Table 6). \%SC, however, was larger in the tetraploid biotype (Table 6).

The coefficient of variability showed that the variation of the vegetative characters in the pentaploid biotype was greater than within the tetraploid biotype, although the difference between biotypes for these characters was not statistically significant (Table 7). The variability in $\mathrm{NSpP}$ was significantly greater in the tetraploid biotype and whereas \%SC was greater in the pentaploid biotype.

We built a phenogram using the GD distance coefficient from representative genotypes of the different populations (Fig. 2b).

Two main groups can be identified: group A that includes mainly pentaploid individuals and group B consisting of tetraploid individuals. Also, a nucleus was formed by two genotypes from the population collected in Magdalena (Mag 146 and Mag149). Finally, one genotype from Brandsen (Br14) was incorporated in the phenogram. These three genotypes also had extreme values of NSP.

Reproductive characters are relevant in the discrimination of individuals. The variation included in the first component is explained by LP and LBSR. NRT and NSP explained the variation in the second and third component, respectively (Table 8).

The cophenetic correlation coefficient (CCC) was $r=0.78$ suggesting that the agreement between the distance matrix and the phenogram was high.

Table 4 Means of vegetative and reproductive characters of Paspalum dilatatum Poir.

\begin{tabular}{|c|c|c|c|c|c|c|c|c|c|c|}
\hline \multirow[t]{2}{*}{ Characters } & \multicolumn{8}{|c|}{ Populations } & \multicolumn{2}{|l|}{ Biotypes } \\
\hline & Belgrano & Brandsen & La Plata & Magdalena & Monte & P.Iraola & Ranchos & San Vicente & Tetraploid & Pentaploid \\
\hline NNT & 3.23 & 3.26 & 3.05 & 3.18 & 3.12 & 3.38 & 3.25 & 3.07 & 2.86 & 3.30 \\
\hline $\mathrm{TL}(\mathrm{cm})$ & 75.40 & 74.05 & 70.07 & 72.93 & 74.16 & 74.99 & 74.11 & 70.99 & 69.23 & 74.63 \\
\hline LFL (cm) & 13.30 & 15.74 & 14.40 & 13.30 & 12.47 & 13.56 & 12.84 & 13.78 & 12.57 & 13.94 \\
\hline $\mathrm{WL}_{2}(\mathrm{~cm})$ & 0.55 & 0.64 & 0.58 & 0.56 & 0.53 & 0.60 & 0.55 & 0.51 & 0.46 & 0.59 \\
\hline $\mathrm{LL}_{2}(\mathrm{~cm})$ & 17.64 & 20.02 & 19.10 & 18.06 & 17.26 & 18.16 & 16.96 & 16.96 & 15.80 & 18.46 \\
\hline $\mathrm{WSL}_{2}(\mathrm{~cm})$ & 0.67 & 0.76 & 0.74 & 0.69 & 0.68 & 0.72 & 0.67 & 0.64 & 0.59 & 0.72 \\
\hline NRT & 10.80 & 8.55 & 9.30 & 13.37 & 10.27 & 12.61 & 13.38 & 13.79 & 12.40 & 11.48 \\
\hline NSP & 4.86 & 4.77 & 4.45 & 4.78 & 4.30 & 4.28 & 4.59 & 5.31 & 4.59 & 4.60 \\
\hline $\mathrm{LP}(\mathrm{cm})$ & 13.52 & 13.68 & 12.34 & 12.93 & 12.86 & 13.19 & 13.05 & 12.29 & 12.04 & 13.24 \\
\hline $\operatorname{LBSR}(\mathrm{cm})$ & 7.12 & 7.27 & 6.28 & 6.66 & 6.93 & 7.44 & 6.99 & 6.22 & 5.96 & 7.14 \\
\hline NSpP & 328.43 & 340.70 & 312.04 & 310.19 & 286.60 & 317.85 & 304.38 & 277.73 & 242.15 & 325.97 \\
\hline$\% \mathrm{SC}$ & 14.17 & 10.70 & 10.50 & 14.55 & 16.11 & 9.00 & 9.69 & 19.63 & 4.63 & 3.14 \\
\hline
\end{tabular}

The values were measured by population and by biotype

NNT $=$ number of nodes per tiller; TL = tiller length; LFL = length of the flag leaf; WFL = width of the flag leaf; $\mathrm{LL}_{2}=$ length of the second leaf; $\mathrm{WL}_{2}=$ width of the second leaf; NRT = number of reproductive tillers; NSP = number of spikes per panicle; LP = length of the panicle; LBSR = length of the basal spike rachis; NSpP $=$ number of spikelets per panicle; $\% \mathrm{SC}=$ percentage of spikelets with caryopse 
Table 5 Means contrast of vegetative and reproductive characters of Paspalum dilatatum Poir., established using Tukey test

\begin{tabular}{|c|c|c|c|c|c|c|c|c|c|}
\hline & LFL & WFL & $\mathrm{WL}_{2}$ & NRT & NSP & LP & LBSR & NSpP & $\% \mathrm{SC}$ \\
\hline Belgrano & $\mathrm{b}$ & $b-c$ & $b-c$ & $a-b$ & $a-b$ & $\mathrm{a}$ & $\mathrm{a}$ & $a-b$ & $a-b-c$ \\
\hline Brandsen & $\mathrm{a}$ & $\mathrm{a}$ & $\mathrm{a}$ & $\mathrm{b}$ & $a-b$ & $\mathrm{a}$ & $\mathrm{a}$ & $\mathrm{a}$ & $b-c$ \\
\hline La Plata & $a-b$ & $a-b-c$ & $a-b$ & $a-b$ & $\mathrm{~b}$ & $\mathrm{~b}$ & $\mathrm{~b}$ & $a-b$ & $b-c$ \\
\hline Magdalena & $\mathrm{b}$ & $a-b-c$ & $a-b-c$ & $a-b$ & $a-b$ & $a-b$ & $a-b$ & $a-b$ & $a-b-c$ \\
\hline Monte & $\mathrm{b}$ & $b-c$ & $a-b-c$ & $a-b$ & b & $a-b$ & $a-b$ & $\mathrm{~b}$ & $a-b$ \\
\hline P. Iraola & $\mathrm{b}$ & $a-b$ & $a-b-c$ & $a-b$ & $\mathrm{~b}$ & $a-b$ & $\mathrm{a}$ & $a-b$ & $b-c$ \\
\hline Ranchos & $\mathrm{b}$ & $\mathrm{b}-\mathrm{c}$ & $b-c$ & $a-b$ & $\mathrm{~b}$ & $a-b$ & $a-b$ & $a-b$ & $\mathrm{~b}-\mathrm{c}$ \\
\hline San Vicente & $a-b$ & $\mathrm{c}$ & $\mathrm{c}$ & $\mathrm{a}$ & $\mathrm{a}$ & $b$ & b & $\mathrm{b}$ & $\mathrm{a}$ \\
\hline
\end{tabular}

Means, within a column, followed by the same letters are not significantly different $(P=0.05)$ according to Tukey's test

$\mathrm{LFL}=$ length of the flag leaf; WFL = width of the flag leaf; $\mathrm{WL}_{2}=$ width of the second leaf; $\mathrm{NRT}=$ number of reproductive tillers; NSP = number of spikes per panicle; LP = length of the panicle; LBSR = length of the basal spike rachis; $\mathrm{NSpP}=$ number of spikelets per panicle; $\% \mathrm{SC}=$ percentage of spikelets with caryopse

Table 6 Student test $(t)$ between biotypes characters means of Paspalum dilatatum Poir.

\begin{tabular}{ll}
\hline & Student $t$ \\
\hline TL & $3.72^{* *}$ \\
LFL & $2.85^{* *}$ \\
WFL & $8.12^{* *}$ \\
$\mathrm{LL}_{2}$ & $2.86^{* *}$ \\
$\mathrm{WL}_{2}$ & $3.93 * *$ \\
NRT & 0.84 n.s. \\
NSP & 0.04 n.s. \\
LBSR & $3.57 * *$ \\
NSpP & $5.39 * *$ \\
$\% S C$ & $7.81 * *$ \\
\hline
\end{tabular}

$\mathrm{TL}=$ tiller length; LFL = length of the flag leaf;

$\mathrm{WFL}=$ width of the flag leaf; $\mathrm{LL}_{2}=$ length of the second leaf; $\mathrm{WL}_{2}=$ width of the second leaf; $\mathrm{NRT}=$ number of reproductive tillers; NSP $=$ number of spikes per panicle; LBSR = length of the basal spike rachis; NSpP = number of spikelets per panicle; $\% \mathrm{SC}=$ percentage of spikelets with caryopse

n.s.: Not statistically significant

** Statistically significant at $P=0.01$ level

\section{Molecular characters}

Out of a total of 29 primers only 10 were polymorphic. These 10 primers generated between 4 and 8 bands that varied in size between 250 and 1700 bp with an average size of $730 \mathrm{bp}$ (Tables 9 and 10). We generated a phenogram based on the similarity matrix (Fig. 2a). Only the phenogram obtained from Simple matching association coefficient is showed because the grouping obtained with both coefficients did not show differences. The value of Cophenetic Correlation Coefficients
(CCC) was 0.75 suggesting that the level of distortion between the matrix and the phenograms was low.

The phenogram clustered individuals from the Brandsen, Pereyra Iraola, Ranchos, and San Vicente populations by place of origin whereas the clustering of the individuals from the other

Table 7 Coefficient of variability of vegetative and reproductive characters in Paspalum dilatatum Poir.

\begin{tabular}{|c|c|c|c|}
\hline \multirow[t]{2}{*}{ Characters } & \multicolumn{2}{|l|}{ Biotype } & \multirow[t]{2}{*}{$U$} \\
\hline & Tetraploid & Pentaploid & \\
\hline NNT & 16.43 & 17.57 & n.s. \\
\hline TL & 15.75 & 15.02 & n.s. \\
\hline LFL & 3.16 & 3.78 & n.s. \\
\hline WFL & 17.39 & 20.33 & n.s. \\
\hline $\mathrm{LL}_{2}$ & 4.19 & 5.23 & n.s. \\
\hline $\mathrm{WL}_{2}$ & 16.27 & 18.05 & n.s. \\
\hline NRT & 72.74 & 73.78 & n.s. \\
\hline NSP & 25.49 & 21.95 & n.s. \\
\hline LP & 17.19 & 14.12 & n.s. \\
\hline LBSR & 17.61 & 17.92 & n.s. \\
\hline NSpP & 25.90 & 4.33 & $*$ \\
\hline$\% \mathrm{SC}$ & 24.40 & 36.49 & $*$ \\
\hline
\end{tabular}

NNT $=$ number of nodes per tiller; $\mathrm{TL}=$ tiller length; $\mathrm{LFL}=$ length of the flag leaf; WFL = width of the flag leaf; $\mathrm{LL}_{2}=$ length of the second leaf; $\mathrm{WL}_{2}=$ width of the second leaf; $\mathrm{NRT}=$ number of reproductive tillers; NSP = number of spikes per panicle; $\mathrm{LP}=$ length of the panicle; $\mathrm{LBSR}=$ length of the basal spike rachis; $\mathrm{NSpP}=$ number of spikelets per panicle; $\% \mathrm{SC}=$ percentage of spikelets with caryopse

$U=$ Mann-Whitney test

n.s.: not statistically significant

* Statistically significant at $P=0.05$ level 
a)

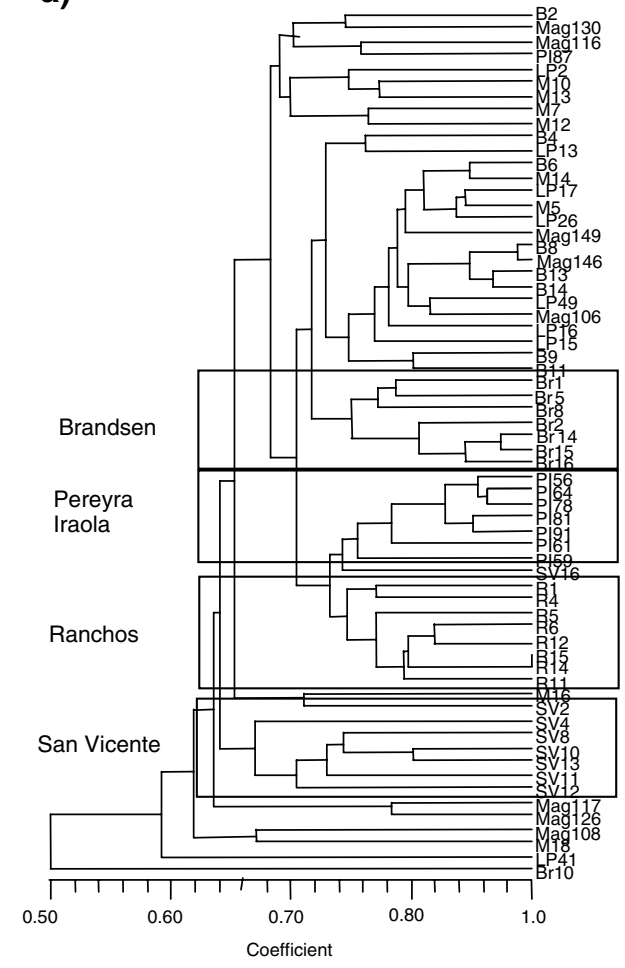

Fig. 2 Cluster analysis phenogram of eight natural population of Paspalum dilatatum Poir. (a) Phenogram generated from molecular similarity matrix. (b) Phenogram

Table 8 Relative significance of vegetative and reproductive characters of Paspalum dilatatum Poir. with respect to the three first principal components

\begin{tabular}{lcrc}
\hline Character & Component 1 & Component 2 & Component 3 \\
\hline RCp & 0.4504 & 0.5886 & 0.3906 \\
NNT & 0.6887 & 0.3745 & -0.2917 \\
TL & 0.6783 & -0.2559 & -0.0695 \\
FAFL & 0.7134 & -00.3545 & 0.3376 \\
FAL 2 & 0.6964 & -0.3445 & 0.3660 \\
NRT & -0.2429 & $\mathbf{0 . 6 6 0 9}$ & -0.2818 \\
NSP & 0.2553 & -0.1761 & $\mathbf{- 0 . 6 6 3 9}$ \\
LP & $\mathbf{0 . 8 2 9 6}$ & -0.0296 & -0.3760 \\
\%SC & -0.4975 & -0.5359 & -0.2762 \\
NSpP & 0.6837 & 0.1643 & 0.1363 \\
LBSR & $\mathbf{0 . 8 1 4 9}$ & 0.0083 & -0.2960
\end{tabular}

$\mathrm{R} C p=$ Resistance to Claviceps paspali $; \mathrm{NNT}=$ number of nodes per tiller; $\mathrm{TL}=$ tiller length; $\mathrm{FAFL}=$ foliar area of the flag leaf; $\mathrm{FAL}_{2}=$ foliar area of the second leaf;

NRT $=$ number of reproductive tillers; NSP $=$ number of spikes per panicle; $\mathrm{LP}=$ length of the panicle;

LBSR = length of the basal spike rachis; $\mathrm{NSpP}=$ number of spikelets per panicle; $\% \mathrm{SC}=$ percentage of spikelets with caryopse

b)

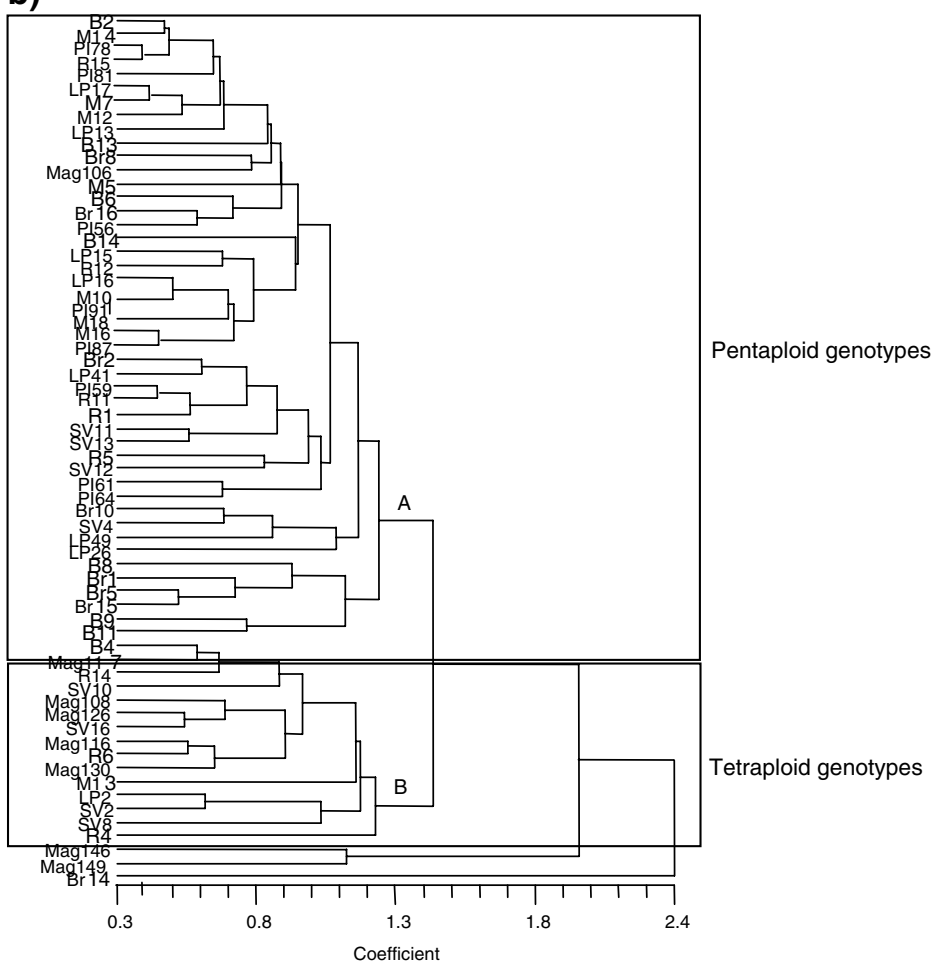

based on the morphological distance matrix. B, Belgrano; Br, Brandsen; LP, La Plata; Mag, Magdalena; M, Monte; PI, Pereyra Iraola; R, Ranchos; SV, San Vicente

populations (Belgrano, La Plata, Magdalena and Monte) showed no relationship with geographic origin.

Bands 12 (1050 bp) and 40 (600 bp) included the variation in the first coordinate. Along this coordinate Pereyra Iraola is grouping. Second coordinate grouping Brandsen and Ranchos. Band 19 (750 bp) explained the variation in this coordinate. Finally, third coordinate grouped San

Table 9 Summary of the results of the amplification reactions performed by means of the primers assayed

\begin{tabular}{ll}
\hline Total number of primers & 29 \\
Number of polymorphic primers & 10 \\
$\begin{array}{l}\text { Percentage of polymorphic primers } \\
\text { Total number of }\end{array}$ & $65.5 \%$ \\
polymorphic bands identified & 60 \\
$\begin{array}{l}\text { Average number of polymorphic } \\
\text { bands per polymorphic primer }\end{array}$ & 6 \\
$\begin{array}{l}\text { Size average of polymorphic primer } \\
\text { Size range of amplified products }\end{array}$ & $730 \mathrm{bp}$ \\
\hline
\end{tabular}


Table 10 Size of polymorphic bands generated with 10 RAPD primers

\begin{tabular}{|c|c|c|c|c|c|}
\hline Primer & Band & Size & Primer & Band & Size \\
\hline \multirow[t]{5}{*}{ A 08} & 1 & $500 \mathrm{bp}$ & \multirow[t]{6}{*}{ OPG 03} & 32 & $320 \mathrm{bp}$ \\
\hline & 2 & $540 \mathrm{bp}$ & & 33 & $420 \mathrm{bp}$ \\
\hline & 3 & $550 \mathrm{bp}$ & & 34 & $550 \mathrm{bp}$ \\
\hline & 4 & $750 \mathrm{bp}$ & & 35 & $650 \mathrm{bp}$ \\
\hline & 5 & $1100 \mathrm{bp}$ & & 36 & 700 bp \\
\hline \multirow[t]{8}{*}{ OPB 15} & 6 & $545 \mathrm{bp}$ & & 37 & $950 \mathrm{bp}$ \\
\hline & 7 & $575 \mathrm{bp}$ & \multirow[t]{5}{*}{ OPG 05} & 38 & $460 \mathrm{bp}$ \\
\hline & 8 & $700 \mathrm{bp}$ & & 39 & $480 \mathrm{bp}$ \\
\hline & 9 & 770 bp & & 40 & $600 \mathrm{bp}$ \\
\hline & 10 & $900 \mathrm{bp}$ & & 41 & $650 \mathrm{bp}$ \\
\hline & 11 & $950 \mathrm{bp}$ & & 42 & $750 \mathrm{bp}$ \\
\hline & 12 & $1050 \mathrm{bp}$ & \multirow[t]{7}{*}{ OPJ 13} & 43 & 480 bp \\
\hline & 13 & $1150 \mathrm{bp}$ & & 44 & $490 \mathrm{bp}$ \\
\hline \multirow[t]{6}{*}{ OPE 09} & 14 & $340 \mathrm{bp}$ & & 45 & $570 \mathrm{bp}$ \\
\hline & 15 & $400 \mathrm{bp}$ & & 46 & $620 b p$ \\
\hline & 16 & $440 \mathrm{bp}$ & & 47 & $850 \mathrm{bp}$ \\
\hline & 17 & $670 \mathrm{bp}$ & & 48 & $1100 \mathrm{bp}$ \\
\hline & 18 & 725 bp & & 49 & $1300 \mathrm{bp}$ \\
\hline & 19 & $750 \mathrm{bp}$ & \multirow[t]{6}{*}{ OPR 04} & 50 & $485 \mathrm{bp}$ \\
\hline \multirow[t]{8}{*}{ OPE 18} & 20 & $250 \mathrm{bp}$ & & 51 & $540 \mathrm{bp}$ \\
\hline & 21 & $345 \mathrm{bp}$ & & 52 & $575 b p$ \\
\hline & 22 & $550 \mathrm{bp}$ & & 53 & $690 \mathrm{bp}$ \\
\hline & 23 & $900 \mathrm{bp}$ & & 54 & $1250 \mathrm{bp}$ \\
\hline & 24 & $1000 \mathrm{bp}$ & & 55 & $1700 \mathrm{bp}$ \\
\hline & 25 & $1100 \mathrm{bp}$ & \multirow[t]{7}{*}{ P 124} & 56 & $400 \mathrm{bp}$ \\
\hline & 26 & $1200 \mathrm{bp}$ & & 57 & $430 \mathrm{bp}$ \\
\hline & 27 & $1350 \mathrm{bp}$ & & 58 & 575 bp \\
\hline \multirow[t]{4}{*}{ OPF 10} & 28 & $270 \mathrm{bp}$ & & 59 & $1250 \mathrm{bp}$ \\
\hline & 29 & $460 \mathrm{bp}$ & & 60 & $1350 \mathrm{bp}$ \\
\hline & 30 & $625 \mathrm{bp}$ & & & \\
\hline & 31 & $1650 \mathrm{bp}$ & & & \\
\hline
\end{tabular}

Vicente. Here the variation is explained by band 46 (620 bp) (data not shown).

\section{Correlation analysis}

The correspondence between morphological traits and RAPD markers was evaluated by means of a Mantel correlation test. The Mantel correlation $(r)$ was 0.02463 and it was not significant, indicating that morphological and molecular markers were unrelated.

\section{Discussion}

Natural populations of $P$. dilatatum in the area sampled are mixtures of two biotypes, each with a distinct breeding system. It results in a complex situation where most plants are apomictic $(5 x)$ and others $(4 x)$ show sexual reproduction.

Efficient genetic characterization depends on levels of variation and in populations that are phenotypically similar unequivocal identification may therefore be complicated. However, high levels of variation within a population can also complicate the analysis (Caetano-Anollés 1998) and different methods and statistical techniques should thus be used to analyze genetic diversity.

Cluster analysis involves techniques that grouping the individuals associated by its similarity level. The grouping pattern of population based on morphological data did not reflect geographical origin. Instead this analysis grouped individuals of the different populations by ploidy level. Two groups were generated; one included pentaploid individuals and the other tetraploid individuals. Garita et al. (1994) reported similar results and suggested that, apart from the anther color and chromosome number, the characters that differentiate biotypes were: glumes pubescence, pedicel length, tiller length, pseudo-stem width, flowering date, pod color and rachilla fragility. Characters LP, LBSR, NRT and NSP allowed us to distinguish between tetraploid and pentaploid biotype (Table 8). Tetraploid and pentaploid individuals can therefore be considered as separate entities with own characteristics (Fig. 2). All vegetative characters were greater in the pentaploid biotype than in the tetraploid biotype and the same was true for all reproductive characters, except \%SC (Table 4).

Even though the mean of reproductive characters were generally greater in the pentaploid biotype, \%SC, the most important reproductive character because it indicates the contribution to the next generation, was higher in the tetraploid biotype, suggesting that the tetraploid biotype has a higher fitness. The higher value of NSP in the pentaploid biotype was compensated by a higher $\% \mathrm{SC}$ in the tetraploid biotype. Production of spikelets with caryopse is 1.5 - fold higher in the tetraploid biotype; tetraploid individuals produced $4.63 \%$ of spiklets with caryopse while pentaploid individuals produced $3.14 \%$. Germination percentage showed similar differences between the two biotypes (data not shown). The percentage of germination was $25.5 \%$ for the 
tetraploid biotype and $16.9 \%$ for the pentaploid biotype. The correlation between \%SC and germination percentage was statistically significant $(P=0.05)$ and $\%$ SC can therefore be used as a predictor of seed fertility. Variation in \% SC, was also lower in the tetraploid biotype compared to the pentaploid biotype.

Skroch et al. (1992) have found that the SM coefficient is an appropriate estimate of relatedness, assuming that among closely related plant materials, both the presence $(1,1)$ and absence $(0,0)$ comparisons of an amplified product in two or more genotypes result from the same genetic changes. Thus both kinds of comparisons provide nearly the same information. The grouping pattern of population based on molecular markers reflected geographical origin and did not reflect ploidy level of the individuals from different populations (Fig. 2). The pattern grouping was generated by differents primers. These results suggest that the populations of Brandsen, Pereyra Iraola, Ranchos and San Vicente, have unique genotypes which makes it possible to identify the geographic place of origin. On the other hand, the populations of Belgrano, La Plata, Magdalena and Monte showed very low levels of differences between them and all individuals clustered in a single, large group. This suggests that these four populations share some genotypes, thereby explaining the high interpopulation similarity. Also, gene flow between pentaploid and tetraploid individuals is possible because both coexist and hybrids can be formed between the two biotypes (Bennett et al. 1969). Bennett et al. (1969) got individuals $2 n=45$ in a cross between both biotypes where the source of pollen was the pentaploid biotype. Chromosomal number in individuals $F_{2}$ varied from 40 to 45 and 20 bivalents and from 0 to 5 univalents during meiosis. These individual $F_{2}$ showed sexual reproduction and heterosis. The cross effectiveness was $0.04 \%$. Reciprocal crosses produced individuals with $2 n=70$ and they were infertile. Also, there is no references to individuals with $2 n=70$ in natural populations composed by tetraploid and pentaploid biotypes in the literature.

Morphological markers did not allow us to discriminate individuals by their geographic origin, probably because these characters are under environmental influence. However, molecular markers might reveal environmental adaptations that are not phenotypically expressed.

Cullis (1999) suggested that plants can develop the ability to respond to environmental pressures. Most of these responses are physiological and involve temporal reactions. However, there are cases of variation at the genome level as a response to environmental pressures. These variations include transposon activation, somaclonal variation, or gene amplification. In an evolutionary context it is necessary to identify regions involved in this type of variation because it will help us to understand how genomic reorganizations can lead to phenotypic variation. In addition, Cullis (1999) suggested that inbreeding species may house little genetic variation if they have been growing in a favorable environment for long time and this can likely be disastrous, unless a mechanism by which variation can be re-introduced or maintained is present. This reasoning can easily be extended to apomictic species as well.

RAPD markers are located at random in the genome. There is no evidence that these markers are located in specific regions (Ferreira and Grattapaglia 1996). In this way is possible to find them in coding or non-coding regions. Bassi (1999) suggested that non-codifying regions can be involved in gene regulation and DNA repetitive regions can modulate between environment and gene expression. In this way, our results might be showing adaptive modifications. Such modifications might generate the differentiation of the populations and the existence of unique genotypes in Brandsen, Pereyra Iraola, Ranchos and San Vicente. Even though the ecological characteristics of these places are very similar, the modifications of the genome might have been generated as the genotypes have adapted to each site, and the genomic structure might have been conserved despite although the fact those environmental pressures are no longer present.

Given the suggestions about the origin of P. dilatatum (Espinoza and Quarín 2000, Casa 1995) our results could indicate that different genomes were involved in the origin of the individuals belonging to the different populations analyzed. The $I$ genome is present in different species of group Quadrifaria. P. quadrifarium 
belongs at this group and this species is a component of the natural pastures (Josifovich et al. 1982) where samples were collected for this study. However, this alternative for explain the origin of both biotypes must be analyzed in detail.

The fact that there was no correspondence between the results obtained from molecular and morphological data suggests that the different types of markers probably are located in different regions of the genome. It could also be the consequence of natural selection on morphology that was not detected by molecular markers because of RAPD markers represents neutral variation.

Moreover, since RAPD did not discriminate between biotypes with sexual or apomictic reproduction, they are probably not associated with mating system.

The results show that polygenic traits such as LP, LBSR, NRT and NSP can be used to discriminate between biotypes whereas molecular markers such as bands $12,40,19$ and 46 can be used to discriminate between populations, probably because they detect neutral variation.

Acknowledgements This study has been funded by grants from the Consejo Nacional de Investigaciones Científicas y Técnicas (1074/98) and from Universidad Nacional de La Plata. We would like to thanks to P.K.Ingvarsson for helpful comments to the manuscript and N. Di Lorenzo for the data on resistance to Claviceps paspali.

\section{References}

Barreto IL (1974) O género Paspalum (Gramineae) no rio grande do Sul. Tesis (Livre Docência). Departamento de Fitotecnia, Facultade do Rio Grande do Sul, Porto Alegre, 258 pp

Bashaw EC, Holt E (1958) Megasporogenesis, embryo sac development and embryogenesis in dallisgrass, Paspalum dilatatum Poir. Agron J 50:753-756

Bassi P (1999) The effect of environmental stress on repetitive DNA behavior in plants. In: Lerner R (ed) Plant responses to environmental stresses. Marcel Dekker, Inc. New York, 730 pp

Bennet HW, Burson BL, Bashaw S (1969) Intraspeciefic hybridization in dallisgrass, Paspalum dilatatum Poir. Crop Sci 9:807-809

Beer SC, Goffreda J, Phillips TD, Murphy JP, Sorrells ME (1993) Assessment of genetic variation in Avena sterilis using morphological traits, isozymes and RFLP. Crop Sci 33:1386-1393
Burkart A (1969) Flora ilustrada de Entre Ríos (Argentina). Parte II. INTA. 551 pp

Burson BL (1991) Genome relationships between tetraploid and hexaploid biotypes of dallisgrass, Paspalum dilatatum. Bot Gaz 152(2):219-223

Burson BL, Bennett HW (1972) Genome relations between an intraspecific Paspalum dilatatum hybrid and two diploid Paspalum species. Can J Genet Cytol 14:609-613

Burson BL, Lee H, Bennett HW (1973) Genome relations between tetraploid Paspalum dilatatum and four diploid Paspalum species. Crop Sci 13:739-743

Burson BL, Voigt PW, Evers GW (1991) Cytology, reproductive behavior, and forage potential of hexaploid dallisgrass biotypes. Crop Sci 31:636-641

Caetano-Anollés G (1998) DNA analysis of turfgrass genetic diversity. Crop Sci 38:1415-1424

Carámbula M (1982) Paspalum dilatatum, características agronómicas y su rol en las pasturas. Revista Argentina de Producción Animal 2:68-84

Casa AM (1995) Caracterizaçao do germoplasma de especies de Paspalum (grupo Dilatata) pelo uso de marcadores bioquimicos e moleculares. Tesis (Mestre em Ciências Biológicas), Instituto de Biociencias, Universidade Estadual Paulista "Julio de Mesquita Filho", Botucatu. 102 pp

Cullis CA (1999) The environment as an active generator of adaptive genomic variation. In: Lerner R (ed) Plant responses to environmental stresses. Marcel Dekker, Inc. New York, 730 pp

Espinoza F, Quarín CL (2000) 2n + n hybridization of apomictic Paspalum dilatatum with diploid Paspalum species. Int J Plant Sci 161(1):221-225

Fernández Grecco RC, Viviani Rossi EM (1997) Guía de reconocimiento de especies de campo natural. INTA Centro regional Buenos Aires Sur. Materiales didácticos $\mathrm{N}^{\circ} 13.67 \mathrm{pp}$

Ferreira ME, Grattaplagia D (1996) Introducao ao uso de marcadores moleculares em analise genética. EMBRAPA - CENARGEN, Documento 20, 220 pp

García MV, Arturi MJ, Ansín OE (2002) Variabilidad fenotípica y genética en poblaciones de Paspalum dilatatum Poir. Agricultura Técnica (Chile) 62(2):237-244

Garita F, Alonso F, Clausen A (1994) Caracterización de subespecies de Paspalum dilatatum Poir. Resúmenes del Congreso Latinoamericano de Botánica. 499 pp

Holt EC (1956) Dallisgrass. Texas Agricultural Experiment Station, EUA Boletín 829. 14 pp

Jarret RL, Liu ZW, Webster RW (1998) Genetic diversity among Paspalum spp. as determined by RFLPs. Euphytica 104:119-125

Josifovich J, Maddaloni J, Serrano H, Echeverría I (1982) Areas forrajeras y de producción animal en la Argentina. Informe Técnico N 169 EEA INTA Pergamino. $110 \mathrm{pp}$

Legendre L, Legendre P (1983) Numerical ecology. Esevier, New York, 419 pp

Liu, ZW, Jarret RL, Duncan RR, Kresovich S (1994) Genetic relationship and variation among ecotypes of seashore paspalum (Paspalum vaginatum) determined by random amplified polymorphic DNA markers. Genome 37:1011-1017 
M'Ribu HK, Hilu KW (1996) Application of random amplified polymorphic DNA to study genetic diversity in Paspalum scrobiculatum L. (Kodo millet, Poaceae). Genet Resour Crop Evol 43:203-210

Ortiz JPA, Pessino SC, Leblanc O, Hayward MD, Quarín CL (1997) Genetic fingerprinting for determining the mode of reproduction in Paspalum notatum, a subtropical apomictic forage grass. Theor Appl Genet 95:850-856

Pahlen A (1986) Evaluation of genetic variability of some native forage plants. Boletín Genético 14:1-6, CICA Castelar

Percival NS, Couchman JN (1979) Evaluation of paspalum (Paspalum dilatatum Poir.) selections. 1. Variation among populations. NZ J Exp Agric 7:59-64

Pereira J, Fajardo A, Sabbía V (1999) Caracterización genética y filogenética del genero Paspalum a partir de marcadores moleculares. Agrociencia 3(1):11-19

Pereira J, Sabbía V, Fajardo A, Speranza PR (2000) Análisis genético en gramíneas nativas del género Paspalum a partir de datos isoenzimáticos y RAPD. Agrociencia 4(1):1-11
Quarín CL, Norrmann GA (1986) Anales del IV Congreso Latinoamericano de Botánica, Medellín. pp 25-34

Skroch P, Tivang J, Nienhuis J (1992) Analysis of genetic relationships using RAPD marker data. En: Proceedings of the Symposium Applications of RAPD technology to plant breeding, Minnesota. pp 26-30

Smouse PE, Long JC, Sokal RR (1986) Multiple regression and correlation extensions of the Mantel test of matrix correspondence. Syst Zool 35(4):627-632

Sneath PHA, Sokal RR (1983) Numerical taxonomy. WH Freeman and Co

Steel RGD, Torrie JH (1980) Principles and procedures of statistics. A biometrical approach, 2nd ed. McGraw Hill Book Company

Steiner JJ, Poklemba CJ, Fjellstrom RG, Elliot LF (1995) A rapid one tube genomic DNA extraction process for PCR and RAPD analyses. Nucl Acids Res 23(13):2569-2570

Stewart CN, Excoffier L (1996) Assessing population genetic structure and variability with RAPD data: application to Vaccinium macrocarpa (American cranberry). J Evol Biol 9:153-171 